\title{
The Toxoplasma gondii Plastid replication and Repair Enzyme Complex, PREX
}

\author{
A. MUKHOPADHYAY ${ }^{1}$, C-Y. CHEN ${ }^{2}$, C. DOERIG ${ }^{3}$, F. L. HENRIQUEZ ${ }^{4}$, C. W. ROBERTS ${ }^{4}$ \\ and M. P. BARRETT ${ }^{1 *}$ \\ ${ }^{1}$ Institute of Biomedical and Life Sciences, Division of Infection and Immunity, Glasgow Biomedical Research Centre, \\ University of Glasgow, Glasgow G12 8TA, UK \\ ${ }^{2}$ Foseph Gottstein Memorial Cancer Research Laboratory, Department of Pathology, University of Washington, Seattle, \\ WA 98195-7705, USA \\ ${ }^{3}$ INSERM U609, Wellcome Centre for Molecular Parasitology, University of Glasgow, 120 University Place, Glasgow, \\ G12 8TA, Scotland, UK. INSERM U609, Global Health Institute, Ecole Polytechnique Fédérale de Lausanne, \\ CH-1015 Lausnne, Switzerland \\ ${ }^{4}$ Strathclyde Institute of Pharmacy and Biomedical Sciences, 27 Taylor Street, University of Strathclyde, \\ Glasgow G4 0NR, UK
}

(Received 4 December 2008; revised 13 February and 4 March 2009; accepted 4 March 2009; first published online 30 April 2009)

\section{SUMMARY}

A plastid-like organelle, the apicoplast, is essential to the majority of medically and veterinary important apicomplexan protozoa including Toxoplasma gondii and Plasmodium. The apicoplast contains multiple copies of a $35 \mathrm{~kb}$ genome, the replication of which is dependent upon nuclear-encoded proteins that are imported into the organelle. In P. falciparum an unusual multi-functional gene, $p f p r e x$, was previously identified and inferred to encode a protein with DNA primase, DNA helicase and DNA polymerase activities. Herein, we report the presence of a prex orthologue in T. gondii. The protein is predicted to have a bi-partite apicoplast targeting sequence similar to that demonstrated on the PfPREX polypeptide, capable of delivering marker proteins to the apicoplast. Unlike the $P$. falciparum gene that is devoid of introns, the $T$. gondii prex gene carries 19 introns, which are spliced to produce a contiguous mRNA. Bacterial expression of the polymerase domain reveals the protein to be active. Consistent with the reported absence of a plastid in Cryptosporidium species, in silico analysis of their genomes failed to demonstrate an orthologue of prex. These studies indicate that prex is conserved across the plastid-bearing apicomplexans and may play an important role in the replication of the plastid genome.

Key words: Apicomplexa, DNA replication, Plasmodium falciparum, Toxoplasma gondii, exon, intron, DNA polymerase, DNA primase, DNA helicase.

\section{INTRODUCTION}

The parasite Toxoplasma gondii is a member of the eukaryotic phylum Apicomplexa. The phylum, which includes Plasmodium falciparum, a causative agent of malaria, as well as multiple other parasitic genera, is of immense medical and veterinary importance. Members of this phylum share a number of structural attributes. With the likely exception of Cryptosporidium, one such shared characteristic is the apicoplast, a relict plastid believed to have been acquired through secondary endosymbiosis (Wilson et al. 1994; McFadden et al. 1996). The T. gondii apicoplast contains its own $\sim 35 \mathrm{~kb}$ genome that is replicated and segregated with the organelle during parasite proliferation. With the exception of the microgamete stage, all $T$. gondii life-cycle stages

* Corresponding author: Institute of Biomedical and Life Sciences, Division of Infection and Immunity, Glasgow Biomedical Research Centre, University of Glasgow, Glasgow G12 8TA, UK. have been demonstrated to possess a single apicoplast, which is faithfully segregated into the daughter cells (Striepen et al. 2000; Ferguson et al. 2007). Like many endosymbiont-derived organelles, the apicoplast has a reduced genome containing genes involved principally in its own replication. A variety of the genes originally associated with the prokaryotic endosymbiont have been incorporated into the nuclear genome and their products are targeted back to the apicoplast using a bi-partite plastid targeting peptide. Consequently, many nuclear-encoded enzymes associated with the apicoplast are of prokaryotic ancestry. The organelle is essential as it is the site for numerous biochemical pathways including heme and fatty acid biosynthesis and steroid production (Roos, 1999; Soldati, 1999; McLeod et al. 2001). The apicoplast has therefore proven to be a valuable target for drugs active against apicomplexan parasites (Fichera and Roos, 1997).

Genes encoding proteins involved in DNA replication or repair are absent from the apicoplast genome. Certain genes encoding plastid DNA replication enzymes are, however, present in the nuclear 
genome, with the protein being imported into the plastid post-translationally. Inhibition of components of the apicoplast DNA replication machinery (e.g. DNA gyrase) by ciprofloxacin (Dar et al. 2007) can cause cessation of apicoplast replication and subsequent parasite death (Dar et al. 2007; Raghu Ram et al. 2007). Thus, the nuclear encoded apicoplast replication machinery is an established drug target in apicoplexan parasites (Ralph et al. 2001).

The various enzymatic activities required for replication of the apicoplast genome in P. falciparum may be derived in large part from a single gene, pfprex, which encodes a multifunctional protein (Seow et al. 2005) comprising a T7 bacteriophage homologous primase-helicase domain and a prokaryotic DNA polymerase domain separated by a spacer domain. An N-terminal sequence of PfPREX targeted Green Fluorescent Protein (GFP) to the apicoplast, strongly suggesting that this protein may be involved in DNA replication or repair of the organelle genome. Thus, this single gene provides multiple functional properties required for apicoplast replication and/or repair (Seow et al. 2005). Herein, we demonstrate the presence of a single prex gene (Tgprex) in T. gondii. Unlike prex in P. falciparum, the gene in $T$. gondii is interrupted by multiple introns. The polymerase domain expressed as a recombinant protein in $E$. coli displays DNA polymerase activity. The conservation of unusual prokaryotic-like DNA replication enzymes across the Apicomplexa indicates that PREX could be a potential target for chemotherapy against this class of organisms.

\section{MATERIALS AND METHODS}

\section{T. gondii tachyzoite preparation and preparation} of $c D N A$

T. gondii tachyzoites (RH strain) were grown in the peritoneum of $\mathrm{BALB} / \mathrm{c}$ mice as previously described (Roberts and Alexander, 1992). Tachyzoites were harvested and washed in sterile phosphatebuffered saline (PBS; $0 \cdot 1 \mathrm{M} \mathrm{NaCl}, 2 \cdot 7 \mathrm{~mm} \mathrm{KCl}, 10 \mathrm{~mm}$ $\mathrm{Na}_{2} \mathrm{HPO}_{4}, 1.76 \mathrm{mM} \mathrm{KH}_{2} \mathrm{PO}_{4}, \mathrm{pH} 7 \cdot 4$ ) by centrifugation at $500 \mathrm{~g}$ for $5 \mathrm{~min}$ at $4{ }^{\circ} \mathrm{C}$ and stored as pellets at $-70{ }^{\circ} \mathrm{C}$. RNA isolation from the tachyzoites was performed using Trizol ${ }^{\circledR}$ (Invitrogen, UK) following a protocol, based on a single-step acid guanidinium thiocyanate-phenol-chloroform for RNA isolation (Chomczynski and Sacchi, 1987).

Complementary DNA (cDNA) was produced from total RNA as previously described (Campbell et al. 2004). In a $13 \mu \mathrm{l}$ volume, $1 \mu \mathrm{g}$ of RNA was added to $1 \mu \mathrm{l}$ of random hexamer mix (Promega, Southampton, UK) and $1 \mu \mathrm{l}$ of a $10 \mathrm{~mm}$ deoxynucleoside triphosphate mixture, incubated at $65{ }^{\circ} \mathrm{C}$ for $5 \mathrm{~min}$, and chilled on ice for $1 \mathrm{~min}$. Then 80 units of RNAsin ribonuclease inhibitor (Promega, UK), $4 \mu \mathrm{l}$ of $5 \times$ first strand buffer $(250 \mathrm{~mm}$ Tris-HCl, $\mathrm{pH}$ $8 \cdot 3,375 \mathrm{~mm} \mathrm{KCl}, 15 \mathrm{~mm} \mathrm{MgCl}_{2}$ ), $1 \mu \mathrm{l}$ of $0 \cdot 1$ м DTT and 200 units of Superscript III reverse transcriptase RNAse $\mathrm{H}^{-}$(Invitrogen, $\mathrm{UK}$ ) were added to the reaction and incubated for $5 \mathrm{~min}$ at $25^{\circ} \mathrm{C}$ followed by $55{ }^{\circ} \mathrm{C}$ for $60 \mathrm{~min}$. Inactivation of the reverse transcriptase was performed by heating at $70{ }^{\circ} \mathrm{C}$ for $10 \mathrm{~min}$.

\section{Identification and sequencing of the prex gene in T. gondii}

Initially the PfPREX homologues were identified in the T. gondii genome project by BLASTP analysis. As the $P$. falciparum gene was AT rich, the protein sequence was used as a query and the protein match was extrapolated to its cognate gene in the genome. The two protein coding genes are situated on chromosome VIIb in the $T$. gondii genome project (www.toxodb.org release 4) (Gajria et al. 2008). Oligonucleotide primers were designed to confirm the prex gene structure by PCR. The primer locations are listed in relation to the actual gene model (Fig. 1A) determined in this study and are listed in order of their positions on the gene (Table 1). Primer pairs for each PCR are designated in Fig. 1A. The primers situated within the consensus exons predicted by different gene prediction algorithms (GLEAN, GlimmerHMM, TwinScan, TwinScan/ Eimeria and TigrScan) are in bold font (Table 1). After confirmation of predicted sequences these primers were coupled with primers from other predicted exons to confirm the coding sequence.

PCR reactions were performed on both genomic and cDNA from $T$. gondii (RH strain) tachyzoites for comparison. One $\mu \mathrm{l}$ of the cDNA or $500 \mathrm{ng}$ of the genomic DNA template was amplified by Expand Hi-Fidelity polymerase enzyme (Roche) using $0 \cdot 2 \mathrm{~mm}$ dNTP mix, $0 \cdot 4 \mu \mathrm{M}$ of sequence specific forward and reverse primers with $1.5 \mu \mathrm{M} / 2 \cdot 0 \mu \mathrm{M}$ of $\mathrm{Mg}^{2+}$ in enzyme-specific buffer. Amplified PCR products from the cDNA were cloned into the pGEM-T Easy vector (Promega) and sequenced to verify the ORF. The cDNA contig was assembled using the Contig Express programme of the Vector NTI suite 9 and 10.

To clarify the 5 ' end of the coding sequence in the prex cDNA, Rapid Amplification of the cDNA end (RACE) was performed on $T$. gondii total RNA. The cDNA was amplified (Superscript III, Invitrogen) using a gene-specific reverse primer (RACE 3) situated in the first exon sequenced (Table 1). A poly-cytosine tail was added to the transcribed cDNA using recombinant terminal transferase (Roche). Nested PCR was performed using a polyguanosine forward primer and 2 gene-specific reverse primers (RACE 2 and RACE 1 respectively) as described in Table 1. 

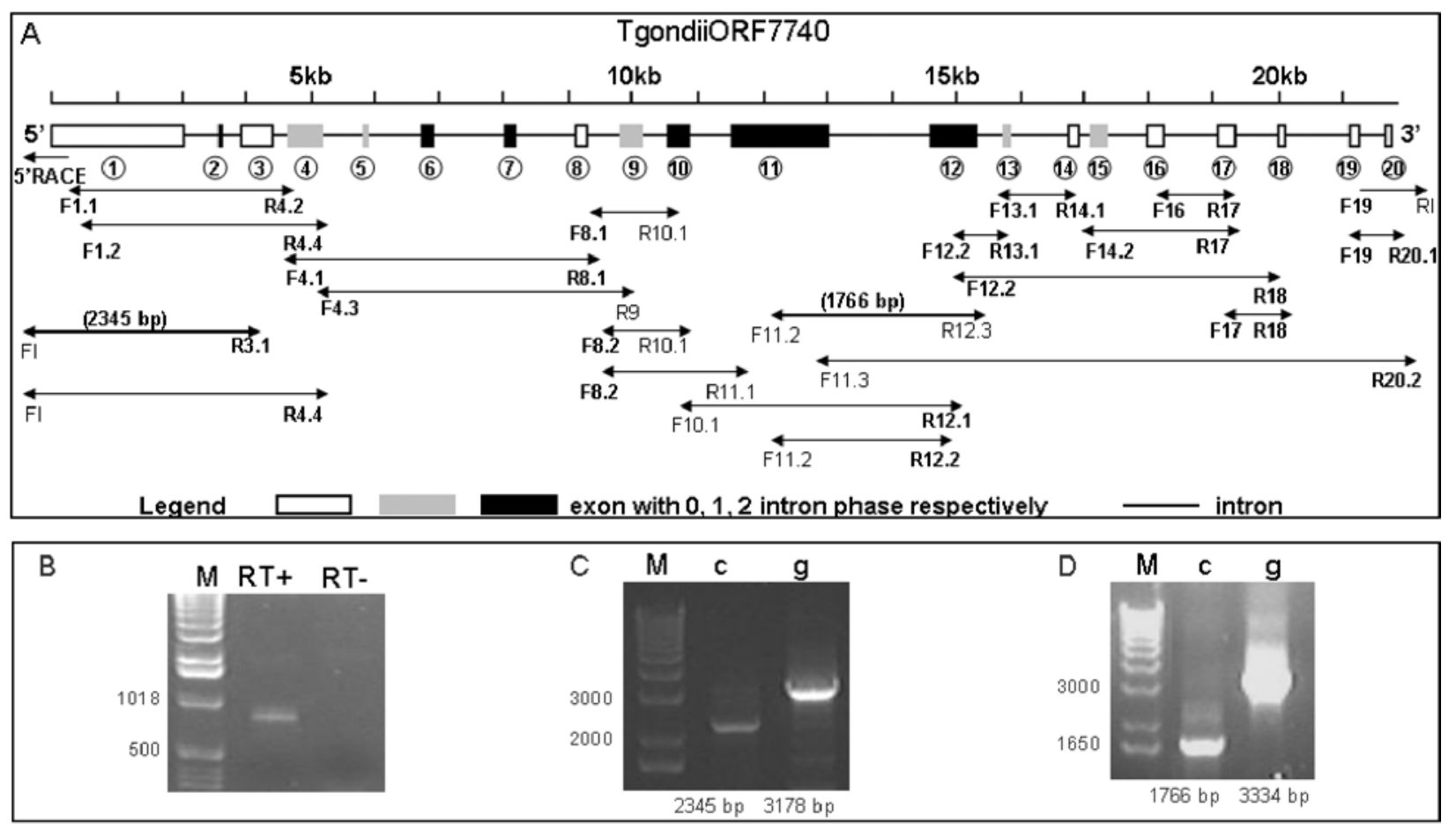

E

TgPREX

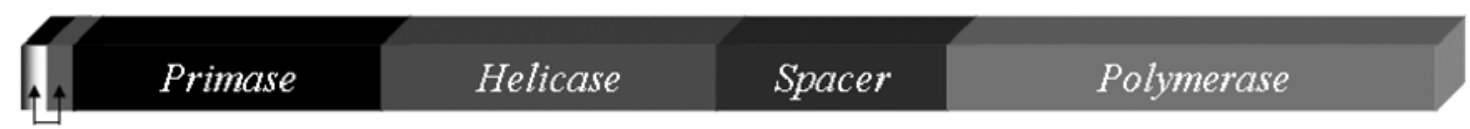

Putative signal and plastid targeting peptides

Fig. 1. The exon-intron structure (Guo et al. 2007) and a diagrammatic representation of the domain structure of the Toxoplasma gondii ORF 7740 present on chromosome VIIb of Toxoplasma gondii as elucidated by PCR. The structure of the $T$. gondii ORF 7740 was confirmed by the sequencing of cDNA from the RH strain of the organism, using primers listed in Table 1 (A). The 7740 bp long ORF was composed of 20 exons separated by 19 introns and different reading frames for the introns are designated. The exon intron structure of the gene was created using GSDS (http://gsds.cbi.pku.edu.cn/) (Guo et al. 2007). Primer pairs used for PCR are delineated in relation to the exon structure of the Tgprex gene. The primers designed on the consensus exon sequences are in bold font. (B) $5^{\prime} \mathrm{RACE}$ was performed to confirm the initiation codon where RT + and RT - refers to reactions with or without reverse transcriptase, respectively. (C) The 5' end of the ORF was confirmed by comparing PCR on cDNA (c) and genomic DNA (g) using primers F.I and R3.1 (Table 1) generating $2345 \mathrm{bp}$ and 3178 bp long PCR products, respectively. (D) The continuity of the single gene was confirmed by PCR using primers F11.2 and R12.3 (Table 1) showing a 1766 bp long PCR product from cDNA (c) compared to a $3334 \mathrm{bp}$ long product from genomic DNA (g). The DNA marker is designated by M. (E) The domain structure of the TgPREX putative protein is diagrammatically represented.

\section{TgPREX polymerase domain cloning and expression}

From the alignment of the predicted PREX proteins in different apicomplexan organisms (data not shown), the exonuclease-polymerase domain of the $T$. gondii PREX was identified and a $3060 \mathrm{bp}$ region encompassing the entire domain was amplified from $T$. gondii tachyzoite cDNA using primers $\mathrm{Tg}_{-}$ polymeraseF and R20.2 (Table 1). The fragment was cloned into the pGEM-T Easy vector and digested with NheI (shown in the Tg_polymeraseF primer in underlined italics in Table 1) and SacI (restriction enzyme site in the pGEM-T Easy plasmid) enzymes, and subsequently ligated into the $\mathrm{pET}^{28 \mathrm{a}^{+}}$vector. In the resulting construct, TgPREX is fused to an
N-terminal hexa-histidine tag and expressed under the control of the $\mathrm{T} 7$ promoter.

The pET28a-TgPREX polymerase plasmid was used for transformation of the $E$. coli BL21-AI (Invitrogen) and cells were grown at $37^{\circ} \mathrm{C}$ in $3 \mathrm{~L}$ of LB medium containing $0 \cdot 1 \%$ glucose and $50 \mu \mathrm{g} / \mathrm{ml}$ carbenicillin; L-arabinose ( $0 \cdot 2 \%$ final concentration) was added at $\mathrm{OD} 600=\sim 0 \cdot 6$. After further incubation for $4 \mathrm{~h}$ at $37^{\circ} \mathrm{C}$, cells were harvested by centrifugation and resuspended in $60 \mathrm{ml}$ of buffer A $[50 \mathrm{~mm}$ Tris-HCl (pH 8.0), $50 \mathrm{~mm} \mathrm{NaCl,} 1 \mathrm{~mm}$ EDTA, $1 \mathrm{~mm}$ PMSF, $2 \mathrm{~mm}$ B-mercaptoethanol, $2 \mathrm{~mm}$ benzamidine and $10 \%(\mathrm{w} / \mathrm{v})$ glycerol], and adjusted to $500 \mu \mathrm{g} / \mathrm{ml}$ lysozyme prior to storage at $-80^{\circ} \mathrm{C}$. 
Table 1. List of primers used for confirmation of the Tgprex gene coding sequence on chromosome VIIb of Toxoplasma gondii and expression of recombinant polymerase domain of TgPREX protein

(The table shows the primer name, nucleotide sequence and the position of each primer according to the sequenced gene model presented in Fig. 1A. Primer pairs used for PCR amplification are delineated in Fig. 1A. The reverse primers are highlighted in the grey background. Primers situated in consensus exons predicted by ToxoDB are in bold font. The 5'RACE primers were used for the clarification of the initiation codon of the gene that was confirmed by PCR amplification of the $5^{\prime}$ region using the 5'UTR primer. The cDNA primers were used to establish the coding sequence of the gene. The 3'UTR primer was used to ensure the 3' end of the Tgprex gene. Polymerase domain of the TgPREX protein was cloned using forward primer Tg_polymeraseF in conjunction with R20.2 reverse primer. The Nhe $I$ restriction site on Tg_polymeraseF primer is shown in italicized font.)

\begin{tabular}{|c|c|c|}
\hline Primer Name & $5^{\prime} \rightarrow 3^{\prime}$ Nucleotide sequence & Location \\
\hline \multicolumn{3}{|l|}{ 5'UTR primers } \\
\hline FI & GCCTCTCCTTGTTCCTGCTTC & $\begin{array}{l}175 \text { bp } 5^{\prime} \\
\text { start codon }\end{array}$ \\
\hline \multicolumn{3}{|l|}{$5^{\prime} \mathrm{RACE}$ primers } \\
\hline RACE.1 & CCAGAGGAGAAAGAACTGTCAC & Exon 1 \\
\hline RACE. 2 & AACGAAGAAAACCGCAGGG & Exon 1 \\
\hline RACE.3 & CGAGAAGGAAAAGACGACG & Exon 1 \\
\hline \multicolumn{3}{|l|}{ cDNA primers } \\
\hline F1.1 & ATGCGTCCGGTTGAGTACCGG & 5'ATG \\
\hline F1.2 & TACTGCCACCGCTGCGGGTGG & Exon 1 \\
\hline R3.1 & CAGCGAGTTCTCTGTCTTCAC & Exon 3 \\
\hline F4.1 & GAAACTCGGAATCGGGAGAT & Exon 4 \\
\hline $\mathbf{R} 4.2$ & TGTCGGGTGTCGGCTCTTCT & Exon 4 \\
\hline F4.3 & AAGGACGCGAACGAGGCGCTC & Exon 4 \\
\hline $\mathbf{R} 4.4$ & CTCAGATCCCTGAAGGTGAGGATTTG & Exon 4 \\
\hline R8.1 & CAACATGAACTGCAAGTTGTC & Exon 8 \\
\hline F8.1 & GACGTAGGCCATGTTGTTCTCGAC & Exon 8 \\
\hline F8.2 & GTTCAGGCGATTCGCCACAGTC & Exon 8 \\
\hline R9 & GAAGTCCGCGACGAGGCAGAG & Exon 9 \\
\hline R10.1 & CCGCTGGTGGGTGCAGCGAGGC & Exon 10 \\
\hline F10.1 & GCCTCGCTGCACCCACCAGCG & Exon 10 \\
\hline R11.1 & CGAAGTGACCTGGAACGCGG & Exon 11 \\
\hline F11.2 & TTTCGTCTCCTCAGCA & Exon 11 \\
\hline F11.3 & ATGCCTCTCCTGCGAGAACTG & Exon 11 \\
\hline R12.1 & GGTCGAATTGTCCGTTATGG & Exon 12 \\
\hline R12.2 & АTCGCTCTGCAAGTCGCCGA & Exon 12 \\
\hline F12.2 & TCGGCGACTTGCAGAGCGAT & Exon 12 \\
\hline $\mathrm{R} 12.3$ & CATGACTCCAGCTTCCACGAC & Exon 12 \\
\hline R13.1 & GTTTCTGTTGAAGGCGTTGC & Exon 13 \\
\hline F13.1 & GCAACGCCTTCAACAGAAAC & Exon 13 \\
\hline R14.1 & СТCTTTCCATCGTGCGTGGTCG & Exon 14 \\
\hline F14.2 & CTCCACCCGATCGTCCTGAA & Exon 14 \\
\hline F16 & CAGCTGCGATTCTCCGAA & Exon 16 \\
\hline R17 & CCGCACTCATTCCATAAATC & Exon 17 \\
\hline F17 & GATTTATGGAATGAGTGCGG & Exon 17 \\
\hline R18 & AAAGTGCTCTCCGTCCTGCG & Exon 18 \\
\hline F19 & CGGCGGTCGGCTGGTCATGTG & Exon 19 \\
\hline $\mathrm{R} 20.1$ & CAACACACGGGACAAAGCGAAG & Exon 20 \\
\hline $\mathrm{R} 20.2$ & CTACGGCTTGTCTGCCCAGCTGTCGGC & Exon 20 \\
\hline \multicolumn{3}{|l|}{$3^{\prime} \mathrm{UTR}$ primer } \\
\hline R.I & CGACTACGCCGGCCGG & $\begin{array}{l}32 \text { bp } 3^{\prime} \\
\text { stop codon }\end{array}$ \\
\hline \multicolumn{3}{|c|}{$\begin{array}{l}\text { TgPREX polymerase } \\
\text { cloning }\end{array}$} \\
\hline Tg_polymeraseF & GGGGGCTAGCATGCCTCTCCTGCGAGAACTG & Exon 11 \\
\hline
\end{tabular}

The cell suspension was thawed, immediately supplemented with $0 \cdot 1 \times$ protease inhibitor cocktail (EMD Biosciences) and sonicated on ice. The following procedures were carried out at $4{ }^{\circ} \mathrm{C}$. After centrifugation at $20000 \boldsymbol{g}$ for $30 \mathrm{~min}$, the supernatant was preserved, and the cell pellet resuspended in $15 \mathrm{ml}$ of buffer $\mathrm{A}$; the sonification and centrifugation steps were repeated and the supernatant fractions were combined (Fraction I). Fraction I was loaded onto a DEAE cellulose (Sigma) column $\left(4.9 \mathrm{~cm}^{2} \times\right.$ $4 \mathrm{~cm}$ ) equilibrated in buffer $\mathrm{A}$ and the column was washed with $100 \mathrm{ml}$ of buffer A. Proteins were eluted by using a $120 \mathrm{ml}$ linear gradient of $50-500 \mathrm{~mm}$ $\mathrm{NaCl}$ in buffer A. Fractions $(5 \mathrm{ml})$ containing DNA 
polymerase activity were pooled (Fraction II) and dialysed against buffer $\mathrm{B}$ [50 mM Tris- $\mathrm{HCl}(\mathrm{pH} 8 \cdot 0)$, $50 \mathrm{~mm} \mathrm{NaCl}, 1 \mathrm{~mm}$ EDTA, 0.1 mм PMSF, 2 mм $\beta$ mercaptoethanol, $2 \mathrm{~mm}$ benzamidine and $10 \%(\mathrm{w} / \mathrm{v})$ glycerol]. Following dialysis, Fraction II was applied to a P-11 (GE Healthcare, Piscataway, NJ) column $\left(1.8 \mathrm{~cm}^{2} \times 7 \mathrm{~cm}\right)$ equilibrated in buffer $\mathrm{B}$. The column was washed with $60 \mathrm{ml}$ of buffer B, followed by elution with a $60 \mathrm{ml}$ linear gradient of $50-500 \mathrm{~mm}$ $\mathrm{NaCl}$ in buffer $\mathrm{B}$. The fractions $(2.5 \mathrm{ml})$ were analysed in $10 \%$ SDS-polyacrylamide gels, and fractions containing DNA polymerase activity were pooled (Fraction III) and dialysed against buffer C $[50 \mathrm{~mm}$ sodium phosphate ( $\mathrm{pH} \mathrm{8.0),} 250 \mathrm{~mm} \mathrm{NaCl}, 10 \mathrm{~mm}$ imidazole, $1 \mathrm{~mm} \beta$-mercatoethanol, $2 \mathrm{~mm}$ benzamidine and $5 \%(\mathrm{w} / \mathrm{v})$ glycerol]. Dialysed Fraction III was loaded onto a Qiagen nickel-nitrilotriacetic acid (Ni-NTA) affinity column $(1.77 \mathrm{~cm} 2 \times 3 \mathrm{~cm})$ equilibrated in buffer $\mathrm{C}$. The column was washed with $25 \mathrm{ml}$ of buffer $\mathrm{C}$ and then with a $30 \mathrm{ml}$ linear gradient of 10-300 mM imidazole (pH 8.0) in buffer C. Fractions $(2.5 \mathrm{ml})$ containing TgPREX polymerase proteins, identified by electrophoresis in $10 \%$ SDS-polyacrylamide gels, were pooled (fraction IV). After dialysis against storage buffer [50 mM Tris$\mathrm{HCl}(\mathrm{pH} 7 \cdot 4), 1 \mathrm{~mm}$ DTT, $30 \mathrm{~mm} \mathrm{NaCl}$ and $10 \%$ (w/ v) glycerol], the preparation was concentrated using an Amicon filter unit (MW cut-off 50000 ). Aliquots were made and stored at $-80{ }^{\circ} \mathrm{C}$. The purified TgPREX polymerase protein (Fraction IV) appeared homogenous, as assessed in a $10 \%$ SDSpolyacrylamide gel followed by the Commassie Blue G-250 staining. Protein concentration was determined by the Bradford reaction (Bradford, 1976) using the Bio-Rad Protein Assay with bovine serum albumin as a standard.

\section{Mass spectrometric analysis of the expressed protein}

The purified protein was used for trypsin digestion (Bridges et al. 2008). Tryptic peptide samples were separated on an LC system (Famos/Switchos/Ultimate, LC Packings) before being analysed by electrospray ionisation (ESI) Mass Spectrometry (MS) on a Q-STAR ${ }^{\circledR}$ Pulsar i hybrid LC/MS/MS System. Peptide separation was performed on a Pepmap C18 reversed phase column (LC Packings), using a $5-85 \% \mathrm{v} / \mathrm{v}$ acetonitrile gradient (in $0.5 \% \mathrm{v} / \mathrm{v}$ formic acid) run over $45 \mathrm{~min}$. The flow rate was maintained at $0 \cdot 2 \mu \mathrm{l} / \mathrm{min}$. Mass spectrometric analysis was performed using a 3-sec survey MS scan followed by up to $4 \mathrm{MS} / \mathrm{MS}$ analyses of the most abundant peptides (3 sec per peak) in Information Dependent Acquisition (IDA) mode, choosing $2+$ to $4+$ ions above threshold of 30 counts, with dynamic exclusion for $120 \mathrm{sec}$.

Data generated from the Q-STAR ${ }^{\circledR}$ Pulsar i hybrid mass spectrometer was analysed using Applied Biosystems Analyst QS (v1.1) software and the automated Matrix Science Mascot Daemon server (v2.1.06). Protein identifications were assigned using the Mascot search engine, which gives each protein a probability-based MOWSE score. In all cases variable methionine oxidation was allowed in searches. An MS tolerance of $1.2 \mathrm{Da}$ for MS and $0.4 \mathrm{Da}$ for MS/MS analysis was used.

\section{DNA polymerase activity assay}

DNA polymerase activity was assayed as described (Glick et al. 2002). Briefly, the activity was measured at $37^{\circ} \mathrm{C}$ for $15 \mathrm{~min}$ in $10 \mu \mathrm{l}$ reaction mixtures containing $1 \mu \mathrm{g}$ of activated calf thymus DNA, $25 \mu \mathrm{M}$ each dNTP, $1 \mu \mathrm{Ci} \alpha\left[{ }^{32} \mathrm{P}\right]$ dTTP $(3000 \mathrm{Ci} / \mathrm{mmol})$ (PerkinElmer, Waltham, MA, USA), and $1 \mu \mathrm{l}$ of enzyme in $30 \mathrm{~mm}$ Tris-HCl, $\mathrm{pH} 7 \cdot 0,10 \mathrm{~mm} \mathrm{MgCl}_{2}$, $1 \mathrm{~mm}$ DTT, $250 \mu \mathrm{g} \mathrm{BSA}$, and $2 \cdot 5 \%$ glycerol. The reaction was terminated by the addition of $100 \mu \mathrm{l}$ of $0 \cdot 1 \mathrm{M}$ sodium pyrophosphate $/ 0 \cdot 05 \mathrm{M}$ EDTA. An aliquot $(100 \mu \mathrm{l})$ of the reaction mixture was transferred to a well in a 96-microwell ${ }^{\circledR}$ plate (Biodyne ${ }^{\circledR}$ B; NUNC ${ }^{\mathrm{TM}}$ ) mounted on a 96-vacuum manifold (Beckman Coulter, Fullerton, CA, USA). The plates were washed 3 times with $250 \mu \mathrm{l}$ of $0 \cdot 1 \mathrm{M}$ sodium pyrophosphate. The filter was removed from the plate, dried, and the amount of radioactivity associated with the filter was quantified by phosphorimager analysis using ImageQuant ${ }^{\circledR}$ software $(\mathrm{GE}$ Healthcare, Piscataway, NJ).

\section{Software}

Vector NTI Advance ${ }^{\text {TM }}$ suite 9 and 10 (Infomax 2003 from Invitrogen) was used for sequence analysis. The exon-intron structure of the Tgprex gene was created using GSDS, a gene structure display software (http://gsds.cbi.pku.edu.cn/) (Guo et al. 2007). SignalP 3.0 Server (http://www.cbs.dtu.dk/ services/SignalP/) (Bendtsen et al. 2004; Nielsen et al. 1997; Nielsen and Krogh, 1998), SIG-Pred (http://www.bioinformatics.leeds.ac.uk/prot_analysis/ Signal.html), SIGFIND (http://139.91.72.10/sigfind/ sigfind.html), PrediSi (Hiller et al. 2004) and ChloroP 1.1 Server (http://www.cbs.dtu.dk/services/ChloroP/ \#submission) (Emanuelsson et al. 1999) were used for signal and transit peptide identification of TgPREX protein.

\section{RESULTS}

\section{Identification of a PREX homologue in ToxoDB}

Two genes (55.m04962/TGME49_061920 and 55.m04960/TGME49_061800) were identified in ToxoDB (release 4 and 5 respectively) on chromosome VIIb of $T$. gondii genomic sequence on contigs 994270 and 994314 in the antisense strand (Kissinger et al. 2003). The coding sequence of this region 
A

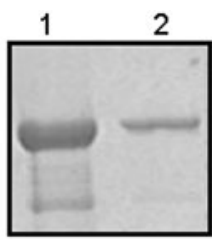

B

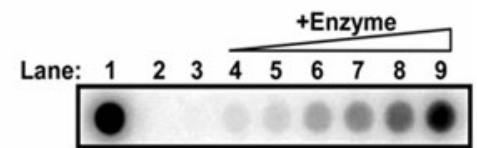

C

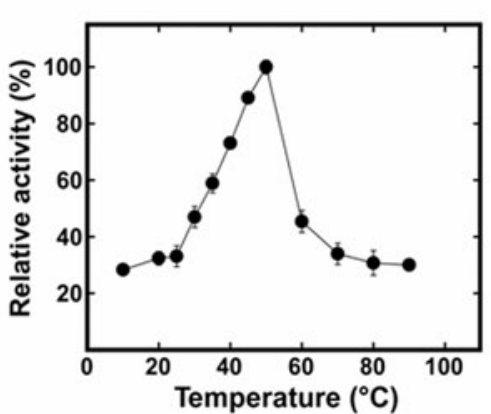

D

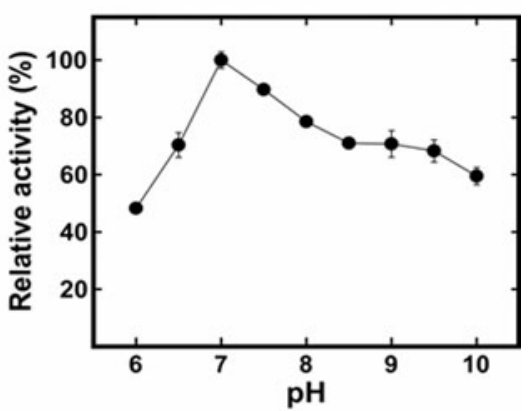

$E$

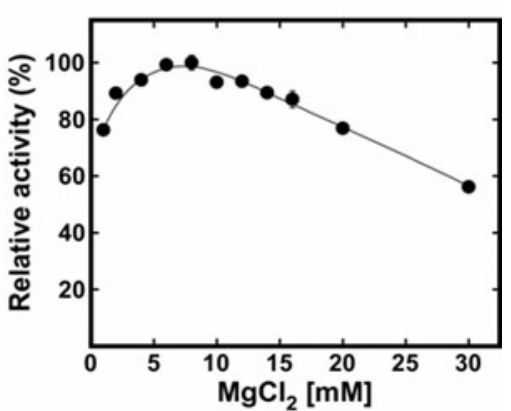

Fig. 2. SDS-PAGE and functional analysis of the purified TgPREX polymerase protein. The SDS-PAGE of purified TgPREX revealed a $114 \mathrm{kDa}$ protein band in purified (2) followed by concentrated (1) protein samples. Functional properties of the purified TgPREX protein. (B) For TgPREX DNA polymerase activity $\mathrm{Mg}^{2+}$ ions are required. In the absence of $\mathrm{Mg}^{2+}$ ions, the amount of incorporated $[\alpha]^{32} \mathrm{P}-\mathrm{dTTP}$ by the TgPREX to the activated calf thymus DNA is similar to that without the enzyme addition (Lanes 3 and 2, respectively). The amounts of incorporated $[\alpha]^{32} \mathrm{P}-\mathrm{dTTP}$ to the activated calf thymus DNA increases as the concentrations $(3 \cdot 1,6 \cdot 3,12 \cdot 5,25,50$ and $100 \mathrm{~nm}$, respectively) of TgPREX increases in the reaction (Lanes 4-9, respectively). The DNA polymerase activity of E. coli Klenow (1 unit) is also shown as a control (Lane 1). (C) TgPREX polymerase activity measured as a function of $\mathrm{MgCl}_{2}$ concentration; (D) TgPREX polymerase activity measured as a function of $\mathrm{pH}$; (E) TgPREX polymerase activity measured as a function of temperature. Error bars represent the standard deviation of 3 independent experimental determinations.

(1 488133 to $1515551 \mathrm{bp}$ ) on chromosome VIIb was clarified by PCR amplification from $T$. gondii $\mathrm{cDNA}$ using primer pairs delineated in Fig. 1A.

Following sequencing, it appeared that a single gene homologous to Pfprex is present in T. gondii cDNA; thereafter, we call this gene Tgprex. The Tgprex gene comprises of 20 exons as shown in Fig. 1A. The $5^{\prime}$ end of the ORF was elucidated by $5^{\prime}$ RACE (Fig. 1B). The initiation codon of the ORF (Fig. 1C) was confirmed by comparing the $2345 \mathrm{bp}$ long sequenced PCR product from the cDNA with that of genomic DNA (Fig. 1C). Sequencing of the $1766 \mathrm{bp}$ long cDNA PCR product in comparison to genomic DNA PCR (Fig. 1D) confirmed the connection between the putative primase-helicase and the polymerase region of the Tgprex gene. The putative domain structure of the translated TgPREX protein is represented in Fig. 1E.

In summary, a 7740 bp long ORF, (TgondiiORF7740/Tgprex, GenBank Accession no. FJ665392) was identified from the sequenced region of chromosome VIIb (between 1,491,400 and 1,512,118). A sequencing gap between contigs 994270 and 994314 in the database was sequenced from both the genomic DNA and the cDNA of the RH strain of the organism and a $146 \mathrm{bp}$ long sequence was subsequently deposited in the database.

\section{Prediction of localization of TgPREX in silico}

The TgPREX translated protein sequence possessed a primase, helicase and polymerase homologous domain structure (Fig. 1E) similar to that of the PREX protein of Plasmodium. The peptide region of the TgPREX protein that separated the primase-helicase and the polymerase domains has no similarity to the spacer region occupying the same region of the PfPREX predicted peptide sequence.

$T$. gondii uses the same general mechanism to mediate transport of proteins into the apicoplast as Plasmodium (He et al. 2001). A bipartite leader peptide, including a primary secretory domain followed by a secondary plastid transit domain, can be predicted by specialized tools including PlasmoAP (Foth et al. 2003) and PATS (Waller et al. 1998; Zuegge et al. 2001) in PlasmoDB. These programmes, however, failed in systemically identifying the apicoplast targeted proteins in T. gondii (Harb et al. 2004). For example, known $T$. gondii nuclear encoded apicoplast proteins (e.g. acyl carrier protein [AAC63956], beta-hydroxyacyl-ACP dehydratase [AAC72191], small ribosomal protein S9 [AAC63957], large ribosomal protein L28 [AAC63958] (Waller et al. 1998) and a putative ferredoxin $\mathrm{NADP}^{+}$oxidoreductase [CAC15394] (Vollmer et al. 2001) were all 
Table 2. PREX homologous genes in other apicomplexa

\begin{tabular}{lll}
\hline \hline Organism & $\begin{array}{l}\text { Gene/Chromosome/ } \\
\text { Contig/Protein }\end{array}$ & Probability \\
\hline $\begin{array}{l}\text { Toxoplasma gondii } \\
\text { Plasmodium yoelii }\end{array}$ & Protein XP_729420 & 2e-136 \\
Plasmodium berghei & Protein XP_679621 & $7 \mathrm{e}-135$ \\
Plasmodium vivax & Protein XP_001616839 & $2 \mathrm{e}-131$ \\
Plasmodium knowlesi & Protein XP_002260883 & $1 \mathrm{e}-129$ \\
Plasmodium falciparum & Protein XP_001348285 & $8 \mathrm{e}-106$ \\
Plasmodium chabaudi & Protein XP_746033 & $4 \mathrm{e}-135$ \\
Theileria annulata & Protein XP_954352 & $9 \mathrm{e}-131$ \\
Theileria parva & Protein XP_765913 & $3 \mathrm{e}-134$ \\
Babesia bovis & Protein XP_001610510 & $4 \mathrm{e}-148$ \\
\hline \hline
\end{tabular}

unrecognized. For each of these proteins, however, the signal peptide component was recognized by SignalP 3.0 and the plastid targeting peptide following the signal peptide was recognized by ChloroP 1.1.

The N-terminal end of the TgPREX protein was analysed sequentially for the presence of a bipartite leader peptide. A 70 amino acid long N-terminal sequence of TgPREX was used as a query in PrediSi and SIGFIND software. Amino acid residues from 30 to 70 were used as a query in SignalP 3.0 as the maximum length of sequence input is restricted to 30 in this programme. All the analyses predicted TgPREX as an apicoplast-localized protein similar to its homologous counterpart PfPREX whose N-terminus was shown to direct GFP to the apicoplast (Seow et al. 2005). TgPREX appears to possess a putative, comparatively long $\mathrm{N}$-terminal signal peptide, 60 to 61 amino acids in length. The cleavage sequence has been identified within the multiple serine residues (VLS-SS or VLSS-SS). The signal peptide was followed by a 61-amino acid long, putative plastid transit peptide as identified by the ChloroP1.1 programme.

\section{Analysis of the PREX polymerase}

The recombinant polymerase domain of the TgPREX, with a predicted mass of $114 \mathrm{kDa}$ was expressed in E. coli. The histidine-tagged protein was purified by $\mathrm{Ni}^{2+}$ affinity chromatography. The protein was analysed by SDS-PAGE and the identity was confimed by mass spectrometry. The identified peptides are detailed in the Supplementary Data 1 (Online version only).

The purified TgPREX polymerase recombinant protein (Fraction IV) (Fig. 2A) was tested for its DNA polymerase activity. Activity was optimal at a temperature of $50{ }^{\circ} \mathrm{C}$ (Fig. 1C) and at $\mathrm{pH} 7 \cdot 0$ (Fig. 1D). The enzyme required $\mathrm{Mg}^{2+}$ ions for activity (Fig. 1B), which reached the optimum at $5 \mathrm{mM} \mathrm{MgCl}_{2}$ (Fig. 1E).
DISCUSSION

PREX, the plastid replication and repair enzyme complex of apicomplexan parasites was first identified in Plasmodium. Homology to DNA primase, helicase and polymerase in other systems indicated that the gene codes for all of these key functions. The presence of a predicted plastid targeting sequence and the fact that a similar sequence in $P$.falciparum guides marker proteins to the apicoplast suggest that PREX is instrumental in the replication of apicoplast DNA.

Among the annotated genes related to Tgprex in ToxoDB, TGME49_061800 expression is linked to one EST (Expressed Sequence Tag) and 7.6 normalized SAGE (serial analysis of gene expression) tag counts (Gajria et al. 2008). There are no such data related to the TGME_061920 gene. Mass spectrometry analysis has identified 2 peptide sequences (ARPLSPEHSALNESAGCAR and LFLESATPVPHAQILTFR) (Xia et al. 2008) which correspond to peptides in exon 4 and 5 of the sequenced Tgprex gene respectively. The lack of good EST coverage for this gene probably corresponds to a low level expression as documented in ToxoDB at the $32 \cdot 2$ and $25 \cdot 2$ percentile for TGME49_061800 and TGME_061920, respectively. A similarly low level of expression was also observed in P.falciparum (Le Roch et al. 2003).

BLAST searches identified full length PREX orthologues in other Plasmodium species, in Theileria parva [XP_765913] and Theileria annulata $\left[\mathrm{XP}_{-}\right.$ 954352] and in Babesia bovis (XP_001610510) (Table 2) (Alignment in Supplementary Data 2 Online version only). Homologues representing fragments of the total predicted protein were also identified in Babesia bigemina, Eimeria tenella, Neospora caninum and Sarcocystis neurona where respective genome sequencing is incomplete. Interestingly, no homologous protein was found in the Cryptosporidium species. Genome sequencing also suggests that Cryptosporidium hominis (Xu et al. 2004) and Cryptosporidium parvum (Abrahamsen et al. 2004) lack an apicoplast. 
Interestingly, the prex gene of $T$. gondii differs from that of $P$. falciparum in that it is interrupted by 20 introns. The intron footprint of eukaryotic, nuclear-encoded genes with possible prokaryotic cyanobacterial ancestry has made a significant contribution to our understanding of gene evolution. The presence of introns in such genes suggests the insertion of introns into pre-assembled genes of eukaryotes late in evolution ('intron late') as the ancestral cyanobacterial genes were devoid of introns. Similar comparison of ribosomal protein S9, L28 and acyl carrier protein genes between P. falciparum and $T$. gondii suggests a process of continuous intron insertion during evolution even after the divergence of Plasmodium and T. gondii from their common ancestor (Schaap et al. 2001).

The polymerase function of this putative protein, identified only in apicoplast-bearing apicomplexans, was confirmed in $T$. gondii. The nuclear encoded PREX appears to serve as a replicative enzyme for the $35 \mathrm{~kb}$ genome of the apicoplast. The participation of nuclear-encoded proteins in apicoplast replication has also been suggested for DNA gyrase subunits A and B (Dar et al. 2007; Raghu Ram et al. 2007), a DNA ligase and 2 hypothetical proteins bearing similarities with DNA-repair proteins (Dahl and Rosenthal, 2008).

Given that inhibitors of other enzymes involved in plastid replication (e.g. inhibitors of DNA gyrase) are toxic to apicomplexan parasites the PREX protein complex may be considered a target for chemotherapy. This may apply particularly to the primase and polymerase domains since the helicase domain has substantial homology to the Twinkle helicase that is active in mitochondria of most eukaryotic species.

We thank Dr Richard J. S. Burchmore of Sir Henry Wellcome Functional Genomics Facility, Institute of Biomedical and Life Sciences, University of Glasgow, for performing the MS analysis of protein in our study. A.M. was funded by the Wellcome Trust as part of their "Molecular Functions in Disease" programme.

\section{REFERENCES}

Abrahamsen, M. S., Templeton, T. J., Enomoto, S., Abrahante, J. E., Zhu, G., Lancto, C. A., Deng, M., Liu, C., Widmer, G., Tzipori, S., Buck, G. A., Xu, P., Bankier, A. T., Dear, P. H., Konfortov, B. A., Spriggs, H. F., Iyer, L., Anantharaman, V., Aravind, L. and Kapur, V. (2004). Complete genome sequence of the apicomplexan, Cryptosporidium parvum. Science 304, 441-445.

Bendtsen, J. D., Nielsen, H., von Heijne, G. and Brunak, S. (2004). Improved prediction of signal peptides: SignalP 3.0. Fournal of Molecular Biology 340, 783-795.

Bradford, M. M. (1976). A rapid and sensitive method for the quantitation of microgram quantities of protein utilizing the principle of protein-dye binding. Analytical Biochemistry 72, 248-254.

Bridges, D. J., Pitt, A. R., Hanrahan, O., Brennan, K., Voorheis, H. P., Herzyk, P., de Koning, H. P. and Burchmore, R. J. (2008). Characterisation of the plasma membrane subproteome of bloodstream form Trypanosoma brucei. Proteomics 8, 83-99.

Campbell, S. A., Richards, T. A., Mui, E. J., Samuel, B. U., Coggins, J. R., McLeod, R. and Roberts, C. W. (2004). A complete shikimate pathway in Toxoplasma gondii: an ancient eukaryotic innovation. International fournal for Parasitology 34, 5-13.

Chomczynski, P. and Sacchi, N. (1987). Single-step method of RNA isolation by acid guanidinium thiocyanate-phenol-chloroform extraction. Analytical Biochemistry 162, 156-159.

Dahl, E. L. and Rosenthal, P. J. (2008). Apicoplast translation, transcription and genome replication: targets for antimalarial antibiotics. Trends in Parasitology 24, 279-284.

Dar, M. A., Sharma, A., Mondal, N. and Dhar, S. K. (2007). Molecular cloning of apicoplast-targeted Plasmodium falciparum DNA gyrase genes: unique intrinsic ATPase activity and ATP-independent dimerization of PfGyrB subunit. Eukaryotic Cell 6, 398-412.

Emanuelsson, O., Nielsen, H. and von Heijne, G. (1999). ChloroP, a neural network-based method for predicting chloroplast transit peptides and their cleavage sites. Protein Science 8, 978-984.

Ferguson, D. J., Campbell, S. A., Henriquez, F. L., Phan, L., Mui, E., Richards, T. A., Muench, S. P., Allary, M., Lu, J. Z., Prigge, S. T., Tomley, F., Shirley, M. W., Rice, D. W., McLeod, R. and Roberts, C. W. (2007). Enzymes of type II fatty acid synthesis and apicoplast differentiation and division in Eimeria tenella. International fournal for Parasitology 37, 33-51.

Fichera, M. E. and Roos, D. S. (1997). A plastid organelle as a drug target in apicomplexan parasites. Nature, London 390, 407-409.

Foth, B. J., Ralph, S. A., Tonkin, C. J., Struck, N. S., Fraunholz, M., Roos, D. S., Cowman, A. F. and McFadden, G. I. (2003). Dissecting apicoplast targeting in the malaria parasite Plasmodium falciparum. Science 299, 705-708.

Gajria, B., Bahl, A., Brestelli, J., Dommer, J., Fischer, S., Gao, X., Heiges, M., Iodice, J., Kissinger, J. C., Mackey, A. J., Pinney, D. F., Roos, D. S., Stoeckert, C. J., Jr., Wang, H. and Brunk, B. P. (2008). ToxoDB: an integrated Toxoplasma gondii database resource, Nucleic Acids Research, 36, D553-D556.

Glick, E., Anderson, J. P. and Loeb, L. A. (2002). In vitro production and screening of DNA polymerase eta mutants for catalytic diversity. Biotechniques 33, 1136-1142, 1144.

Guo, A. Y., Zhu, Q. H., Chen, X. and Luo, J. C. (2007). [GSDS: a gene structure display server]. Yi. Chuan 29, 1023-1026.

Harb, O. S., Chatterjee, B., Fraunholz, M. J., Crawford, M. J., Nishi, M. and Roos, D. S. (2004). Multiple functionally redundant signals mediate 
targeting to the apicoplast in the apicomplexan parasite Toxoplasma gondii. Eukaryotic Cell 3, 663-674.

He, C. Y., Striepen, B., Pletcher, C. H., Murray, J. M. and Roos, D. S. (2001). Targeting and processing of nuclear-encoded apicoplast proteins in plastid segregation mutants of Toxoplasma gondii. Fournal of Biological Chemistry 276, 28436-28442.

Hiller, K., Grote, A., Scheer, M., Munch, R. and Jahn, D. (2004). PrediSi: prediction of signal peptides and their cleavage positions. Nucleic Acids Research 32, W375-W379.

Kissinger, J. C., Gajria, B., Li, L., Paulsen, I. T. and Roos, D. S. (2003). ToxoDB: accessing the Toxoplasma gondii genome. Nucleic Acids Research 31, 234-236.

Le Roch, K. G., Zhou, Y., Blair, P. L., Grainger, M., Moch, J. K., Haynes, J. D., De, L. V., Holder, A. A., Batalov, S., Carucci, D. J. and Winzeler, E. A. (2003). Discovery of gene function by expression profiling of the malaria parasite life cycle, Science 301, 1503-1508.

McFadden, G. I., Reith, M. E., Munholland, J. and Lang-Unnasch, N. (1996). Plastid in human parasites. Nature, London 381, 482.

McLeod, R., Muench, S. P., Rafferty, J. B., Kyle, D. E., Mui, E. J., Kirisits, M. J., Mack, D. G., Roberts, C. W., Samuel, B. U., Lyons, R. E., Dorris, M., Milhous, W. K. and Rice, D. W. (2001). Triclosan inhibits the growth of Plasmodium falciparum and Toxoplasma gondii by inhibition of apicomplexan Fab I. International Fournal for Parasitology 31, 109-113.

Nielsen, H., Engelbrecht, J., Brunak, S. and von Heijne, G. (1997). Identification of prokaryotic and eukaryotic signal peptides and prediction of their cleavage sites. Protein Engineering Design and Selection 10, 1-6.

Nielsen, H. and Krogh, A. (1998). Prediction of signal peptides and signal anchors by a hidden Markov model. Proceedings of the International Conference on Intelligent Systems for Molecular Biology 6, 122-130.

Raghu Ram, E. V., Kumar, A., Biswas, S., Kumar, A., Chaubey, S., Siddiqi, M. I. and Habib, S. (2007).

Nuclear gyrB encodes a functional subunit of the Plasmodium falciparum gyrase that is involved in apicoplast DNA replication. Molecular and Biochemical Parasitology 154, 30-39.

Ralph, S. A., D’Ombrain, M. C. and McFadden, G. I. (2001). The apicoplast as an antimalarial drug target. Drug Resistance Updates 4, 145-151.

Roberts, C. W. and Alexander, J. (1992). Studies on a murine model of congenital toxoplasmosis: vertical disease transmission only occurs in BALB/c mice infected for the first time during pregnancy. Parasitology 104, 19-23.

Roos, D. S. (1999). The apicoplast as a potential therapeutic target in Toxoplasma and other apicomplexan parasites: some additional thoughts. Parasitology Today 15, 41.

Schaap, D., van Poppel, N. F. and Vermeulen, A. N. (2001). Intron invasion in protozoal nuclear encoded plastid genes. Molecular and Biochemical Parasitology 115, 119-121.

Seow, F., Sato, S., Janssen, C. S., Riehle, M. O., Mukhopadhyay, A., Phillips, R. S., Wilson, R. J. and Barrett, M. P. (2005). The plastidic DNA replication enzyme complex of Plasmodium falciparum. Molecular and Biochemical Parasitology 141, 145-153.

Soldati, D. (1999). The apicoplast as a potential therapeutic target in and other apicomplexan parasites. Parasitology Today 15, 5-7.

Striepen, B., Crawford, M. J., Shaw, M. K., Tilney, L. G., Seeber, F. and Roos, D. S. (2000). The plastid of Toxoplasma gondii is divided by association with the centrosomes. Fournal of Cell Biology 151, 1423-1434.

Vollmer, M., Thomsen, N., Wiek, S. and Seeber, F. (2001). Apicomplexan parasites possess distinct nuclear-encoded, but apicoplast-localized, plant-type ferredoxin-NADP + reductase and ferredoxin. Fournal of Biological Chemistry 276, 5483-5490.

Waller, R. F., Keeling, P. J., Donald, R. G., Striepen, B., Handman, E., Lang-Unnasch, N., Cowman, A. F., Besra, G. S., Roos, D. S. and McFadden, G. I. (1998). Nuclear-encoded proteins target to the plastid in Toxoplasma gondii and Plasmodium falciparum. Proceedings of the National Academy of Sciences, USA 95, 12352-12357.

Wilson, R. J., Williamson, D. H. and Preiser, P. (1994). Malaria and other Apicomplexans: the "plant" connection. Infectious Agents and Disease 3, 29-37.

Xia, D., Sanderson, S. J., Jones, A. R., Prieto, J. H., Yates, J. R., Bromley, E., Tomley, F. M., Lal, K., Sinden, R. E., Brunk, B. P., Roos, D. S. and Wastling, J. M. (2008). The proteome of Toxoplasma gondii: integration with the genome provides novel insights into gene expression and annotation, Genome Biology 9, R116.

Xu, P., Widmer, G., Wang, Y., Ozaki, L. S., Alves, J. M., Serrano, M. G., Puiu, D., Manque, P., Akiyoshi, D., Mackey, A. J., Pearson, W. R., Dear, P. H., Bankier, A. T., Peterson, D. L., Abrahamsen, M. S., Kapur, V., Tzipori, S. and Buck, G. A. (2004). The genome of Cryptosporidium hominis. Nature, London 431, 1107-1112.

Zuegge, J., Ralph, S., Schmuker, M., McFadden, G. I. and Schneider, G. (2001). Deciphering apicoplast targeting signals-feature extraction from nuclearencoded precursors of Plasmodium falciparum apicoplast proteins. Gene 280, 19-26. 